\title{
La insoportable levedad de los huesos: memoria, emoción y pedagogía en Chile, la memoria obstinada y Nostalgia de la luz de Patricio Guzmán
}

The Unbearable Lightness of Bones: Memory, Emotion, and Pedagogy in Chile, la Memoria Obstinada and Nostalgia de la luz by Patricio Guzmán A insuportável leveza dos ossos: memória, emoção e pedagogia no Chile, la memoria obstinada e Nostalgia de la luz de Patricio Guzmán

\section{Brad S. Epps}

UNIVERSITY OF CAMBRIDGE, REINO UNIDO

Catedrático de Español y Director del Departamento de Español y

Portugués de la Universidad de Cambridge, Reino Unido. PhD,

Brown University. Autor, junto con Despina Kakoudaki, de All About

Almodóvar: A Passion for Cinema (Minneapolis: University of Minnesota

Press, 2009), entre otros libros. Entre sus últimas publicaciones se

encuentran: "Echoes and Traces: Catalan Cinema, or Cinema in

Catalonia". A Companion to Spanish Cinema (Chichester: Blackwell, 2013. 50-80), "La mirada morbosa en el cine de la Transición Española."

Feminidades y masculinidades: arquetipos y prácticas de género.

Coord. Mary Nash (Madrid: Alianza Editorial, 2014. 243-270). En abril de 2013 fue elegido como miembro de la Reial Acadèmia de les Bones Lletres de Barcelona. Correo electrónico: be243@cam.ac.uk

Artículo de reflexión

Documento accesible en línea desde la siguiente dirección: http://revistas.javeriana.edu.co doi: 10.11144/Javeriana.cl20-39.ilhm 


\section{Resumen}

A través de dos documentales de Patricio Guzmán, Chile, la memoria obstinada (1997) y Nostalgia de la luz (2010), se examinan algunas de las relaciones entre la violencia neoliberal (tanto dictatorial como postdictorial), la memoria, el saber y la emotividad, en su doble vertiente histórica y personal.Junto a las acciones, narraciones y experiencias de un grupo de astrónomos, arqueólogos y geólogos que trabajan en el desierto de Atacama y las de un grupo de mujeres que buscan los restos de sus seres queridos en el mismo desierto, también se realiza una meditación sobre las posibilidades y limitaciones del quehacer cinematográfico en relación con la fotografía y la escritura "celeste" y "terrestre".

Palabras clave: memoria; postmemoria; desaparecidos; Atacama; emoción; pedagogía; neoliberalismo; violencia

\section{Abstract}

By means of two documentaries by Patricio Guzmán, Chile, la memoria obstinada (1997) and Nostalgia de la luz (2010), we examine some of the relationships between neoliberal violence (both, during the dictatorship and after it), memory, knowledge, and emotive nature, in its double aspect, historical and personal. Along the actions, narrations, and experiences of a group of astronomers, archaeologists, and geologists who work in the Atacama Desert, and those of a group of women who look for the remains of their loved ones in the same place, it carries out some deep reflection about the possibilities and limitations of the cinematographic work related to photography and "celestial" and "terrestrial" writing.

Keywords: memory; postmemory; disappeared people; Atacama; emotion; pedagogy; neoliberalism; violence

\section{Resumo}

Através de dois documentários de Patricio Guzmán, Chile, la memoria obstinada (1997) e Nostalgia de la luz (2010), examinam-se algumas das relações entre violência neoliberal (tanto ditatorial quanto pós-ditatorial), a memória, saber e emotividade, na sua vertente dupla histórica e pessoal. Junto às ações, narrações e experiências de um grupo de astrónomos, arqueólogos e geólogos que trabalham no deserto de Atacama e as de uma turma de mulheres que procuram os restos dos seres queridos no mesmo deserto, também é realizada uma meditação sobre as possibilidades e limitações do quefazer cinematográfico em relação com a fotografia e a escrita "celeste" e "terrestre".

Palavras-chave: memória; pós-memória; desaparecidos; Atacama; emoção; pedagogia; neoliberalismo; violência

\section{Cómo citar este artículo:}

Epps, Brad S. "La insoportable levedad de los huesos: memoria, emoción y pedagogía en Chile, la memoria obstinada y Nostalgia de la luz de Patricio Guzmán". Cuadernos de Literatura 20.39 (2016): 338-355. http://dx.doi.org/10.11144/Javeriana.cl20-39.ilhm 
"Tu silencio es de estrella, tan lejano y sencillo" PABLO NERUDA, 20 POEMAS DE AMOR Y UNA CANCIÓN DESESPERADA

"Helo allí Helo allí suspendido en el aire

El Desierto de Atacama" RAÚL ZURITA, PURGATORIO

"En el ocaso de la disolución, todo está iluminado por el aura de la nostalgia, incluso la guillotina" MILAN KUNDERA, LA INSOPORTABLE LEVEDAD DEL SER

No LES PRESENTO un bronce bien forjado, ni un soneto bien escandido, ni una investigación magistral, ni mucho menos una contribución al dudoso arte académico de aventajar a los demás, sino tan solo una triste dispersión de fragmentos, algunos opacos, otros centelleantes, pero únicamente porque brillan con el destello de lo que algunos podrían llamar un "evento desafortunado", es decir, un desastre. Como un arqueólogo verbal, me apropiaría de la palabra "desastre" por su carga etimológica: "de[l prefijo] des-, en este caso simplemente peyorativo + astro 'estrella, planeta, del latín astrum y el griego astron. El sentido es astrológico, de una calamidad que se atribuye a la posición desfavorable de un planeta" ("Disaster", traducción mía). Para quien haya visto el bello, lírico y meditativo documental Nostalgia de la luz (2010) de Patricio Guzmán, mi elección de términos, mi combinación de metáforas, dista mucho de ser arbitraria. Porque en este extraordinario filme del director de la célebre La batalla de Chile (1973-1979), hito del cine comprometido, unos astrónomos y arqueólogos entran en diálogo, a través del acto cinematográfico, con un grupo de mujeres, algunas bastante mayores, que siguen buscando los huesos astillados y los restos desparramados de sus seres queridos casi cuarenta años después de su detención y desaparición. El sitio del encuentro es el desierto de Atacama en el norte de Chile, el lugar más árido del planeta, una vasta región donde el aire es tan seco que hace las veces de una gran máquina momificadora; el evento que motiva el encuentro, tantos años después, es un desastre provocado no por las estrellas 
sino por los seres humanos en forma del golpe militar del 11 de septiembre de 1973 que, con la asesoría y el apoyo del gobierno de los Estados Unidos de América, derrocó al presidente Salvador Allende, democráticamente elegido por el pueblo chileno, e instaló en su lugar al general Augusto Pinochet como dictador. Sucesos pasados en un lugar apartado informan, pues, los fragmentos que aquí examinaré a fin de abordar, entre otras cosas, la compleja interacción entre la memoria y la historia, el conocimiento local y el poder global, la insoportable levedad del ser (abstracto, luminiscente, metafísico) y la no menos soportable levedad de los huesos (concretos, opacos, físicos).

Todos estos asuntos, temas y objetos de estudio, ahora de sobra conocidos, evocan otros, sin embargo, cuyas implicaciones subjetivas y ramificaciones emocionales son tan insistentes como variadas. De ahí que uno de mis objetivos sea arrojar un poco de luz - refractada y esporádica - sobre el sujeto que presume saber, de modo particular el crítico académico, y al hacerlo, interrogar la fuerza de la distancia, tanto temporal como espacial, que ha sido consagrada, pero también cuestionada, como pieza clave del valor intelectual de acuerdo con el cual se espera que nosotros, como críticos, nos separemos de los objetos -y de los sujetos- de nuestras investigaciones a fin de efectuar un examen imparcial y objetivo. Aquí también la etimología resulta instructiva, porque las palabras "crítica" y "crítico", relacionadas con la palabra "crisis" (primo semántico de la palabra "desastre"), provienen del griego krinein, que significa "separar" y "decidir", y remiten a la raíz proto-indoeuropea "krei- [que significa] 'tamizar, discriminar [y] distinguir", ligadas al latín "cribrum 'tamiz' o "criba' y al islandés medieval "crich 'borde, límite'." ("Crisis", traducción mía). Por lo tanto, la tarea del crítico y de la crítica, al menos si somos fieles al etymon o "verdadero sentido" de la etimología, consiste en separar, tamizar, discriminar y decidir, en demarcar, trazar y respetar límites y fronteras, a fin de conocer e incluso "dominar" algo que es diferente al sujeto crítico, algo supuestamente desconectado y apartado del ser que presume saber, del investigador, del buscador. Los estratos geológicos y los planos astrales parecerían proporcionar justo el tipo de distancia y separación que el investigador crítico necesitaría para realizar su trabajo del modo presuntamente más puro y normativamente valorado. Guzmán parece estar al tanto de semejantes expectativas, pero también parece saber que el sujeto que investiga y que busca es, por mucho que se dedique a la objetividad, también un sujeto sensible, un individuo sujeto al sentimiento en todas sus variantes.

Es con el sentimiento en mente (el juego de palabras es intencional) que estaré leyendo Nostalgia de la luz a la luz de una película anterior de Guzmán, 
Chile, la memoria obstinada (1997), que a su vez se centra en el visionado, en el ámbito del aula, de La batalla de Chile. Al hacerlo, espero dejar claro que Nostalgia de la luz, con sus grandiosos gestos metafísicos, panoramas cósmicos y paisajes sublimes, está saturada de emoción — de modo más memorable en la presencia de las mujeres que escarban el desierto buscando los huesos de sus seres queridos y en los testimonios de ellas y de los amigos e hijos de los desaparecidos. También espero sugerir que Nostalgia de la luz está dotada de una pasión pedagógica que hace del desierto de Atacama lo que Alejandro Valenzuela llama "un libro abierto" (119) y lo que yo llamaría un aula sin límites, cuya singular aridez se humedece con las lágrimas de un sinnúmero de espectadores, y cuya intimidante y asombrosa inmensidad se hace misteriosamente familiar con los recuerdos del mismo Guzmán. Como aclara Valenzuela:

la pregunta por la memoria que el documental instala, no pretende establecerse en los dominios de lo objetivo. Desde el comienzo [...] lleva las marcas subjetivas del trazado autobiográfico del propio Guzmán, y emerge precisamente desde el espacio doméstico de su infancia. (119)

He aquí una lección, y es que el saber y el aprendizaje de todo lo que es alto y duro, de las estrellas y de los huesos, están marcados por los sentimientos, por unas sensaciones de involucramiento y apego emocionales.

Ahora bien, en muchos ambientes académicos, incluidos los de las llamadas "Humanidades", ocurre todo lo contrario: los estudiosos cuidadosamente evitan, desestiman, repudian e incluso ridiculizan el apego emocional, la identificación intersubjetiva, la empatía, la simpatía, la compasión, el "co-sentimiento" y otros giros emocionales, viéndolos como faltas y deficiencias de la habilidad intelectual, cuyos fríos cálculos supuestamente salvaguardan a la crítica, desinteresada y desapasionada, de las trampas de los sentimientos y del pantano empalagoso que es, para algunos, todo lo que tiene que ver con la emotividad. Las críticas de la sentimentalidad son cuantiosas y, con frecuencia, derivan del razonamiento radical: la emoción puede ser manipulada y manipuladora, sin duda, y la compasión puede resultar, como acertadamente señalan Walescka Pino-Ojeda y Mariana Ortega Breña, una añagaza retórica que sostiene compulsivamente la "privatización de los sentimientos" que alimenta el "olvido jurídico" y el asalto neoliberal a la esfera pública (136, traducción mía). Pero el repudio del sentimiento, a pesar de su potencial radical, también puede estar, de acuerdo con lo que apunta Nelly Richard, "en pasiva conformidad con el tono insensible - 'desafectivizado' - de los medios de masas" y de cierta investigación sociológica en la que la "racionalidad técnica y [...la] eficacia metodológica [sirven] como muestras de una distancia 
del conocimiento" (Residuos 46,48$)^{1}$. En definitiva, las críticas de la sentimentalidad también pueden ser cómplices del razonamiento neoliberal y de modo tal que resultaría problemático, si no nefasto, arrojar atropelladamente al basurero de la historia todo lo relativo a los sentimientos. En una época en la que las ramas más abstractas y teóricas del saber científico tienen que justificarse en términos mercantilistas de utilidad y rentabilidad, no es de sorprender que las humanidades y los sectores más culturales de las ciencias sociales, como la antropología, una y otra vez tengan que acudir ansiosamente a enfoques "científicos" que pretendan demostrar que el arte, la literatura y la cultura pueden ser abordados, analizados y captados, si no de una manera completamente cuantificable, por lo menos de una manera consistente con un orden económico en el que capitalistas de riesgo y emprendedores ávidos dominan cada vez más las universidades del mundo entero y acaban naturalizando y convalidando el carácter neoliberal que está en el centro de los debates en el Chile post-dictatorial.

Las reflexiones anteriores no son incidentales: toda la obra de Guzmán, desde sus inicios tumultuosos hasta sus finales engañosamente tranquilos, está inmersa en contiendas, a la vez simbólicas y materiales, en las cuales lo económico bien puede resultar determinante en última instancia —al menos en este pequeño planeta. Al ver una película de Guzmán el espectador no puede dejar de lado dichas preguntas y realidades, tal vez especialmente si forma parte de uno de esos pequeños universos conocidos - y desconocidos- como universidades. En la actual universidad neoliberal, ya sea en los Estados Unidos, Chile, el Reino Unido o incluso México, países en los que, a pesar de sus diferencias, la educación se concibe cada vez más en relación con el impacto y el éxito monetarios y a expensas de los pobres, los desempleados, los subempleados, los inmigrantes y muchos "otros" considerados como "improductivos", la objetividad científica y la pureza estética funcionan como los señuelos fetichizados de un mercado en el que la "libertad" se convierte en una condición del comercio más que de la humanidad en toda su diversidad fracturada. Como señala Ernesto Laclau, la objetividad (social) necesariamente presupone la represión de lo que su instalación excluye (citado en Richard, Residuos 29). De acuerdo con Richard, quien cita a Laclau en uno de sus ensayos brillantes sobre la postdictadura chilena, lo que ha sido excluido como contrario a la "objetividad" no es solo el proyecto de justicia

1 Al igual que Richard, Pino-Ojeda y Ortega Breña cuestionan el "distanciamiento ético y emocional" (135, traducción mía) que fomenta la perpetuación racionalizada del orden económico existente y abogan por películas y otras prácticas artísticas que movilizan el "carácter performativo del acto de escuchar" (144, traducción mía) y de ver y que perciben tanto "memorias traumáticas 'individuales' [...] como socialmente compartidas" (135, traducción mía). 
social y económica que defendía la Unidad Popular, proyecto que, en su violenta derrota, ha sido calificado de utópico, soñador e irracional, y que el mismo Patricio Guzmán en las escenas iniciales de Nostalgia de la luz, melancólicamente designa como "una aventura noble". Lo que también ha sido excluido, siempre según Richard, es toda la turbia y recalcitrante carga emocional de un pasado de terror y violencia del estado, toda aquella emoción a la vez popular y personal, colectiva e individual, que no se deja cohesionar ni mucho menos "desaparecer" como pasado. El pasado persiste en el presente, lo informa pues, pero lo informa de una manera persistentemente vacilante, a caballo entre el olvido y el recuerdo, la esperanza y la melancolía, la futuridad y la nostalgia.

Después de todo, Nostalgia de la luz propone, por medio de uno de los sujetos científicos más autorizados, un astrónomo, que el pasado es todo lo que hay, que la luz de las estrellas que llega a nuestros ojos puede tener millones de años, y lo que resulta aún más perturbador, que la luz que alcanza un cuerpo visible desde otro está milisegundos en el pasado. El presente, recuerden, es -o más bien, fue- el momento del idilio infantil, aquella época mítica y sin historia que Nostalgia de la luz evoca, a través de la voz del propio Guzmán, desde el comienzo del documental. Filosófica en su planteamiento conceptual y romántica en su estilo enunciativo, esta concepción del tiempo también es profundamente política. Patrick Blaine, en una sutil reseña de los documentales postdictatoriales de Guzmán, observa que la "[m]emoria histórica es [...] antitética a la ideología neoliberal, la cual estriba en la 'obsolescencia forzada' [y que] crea un presente esencialmente desprovisto de significado sustancial" (121), un presente en el cual el pasado no importa. Blaine concuerda con Richard, para quien, "el consenso oficial de la Transición [de la dictadura a la democracia] desechó [la] memoria privada de los des-acuerdos" (Residuos 29). A la vez autocongratulatorio y cohibido, dicho consenso "reprime [la] desatadura emocional del recuerdo [y] sólo nombra a la memoria con palabras exentas de toda convulsión de sentido" (Residuos 31). "Pareciera, entonces", declara Richard, "que el consenso político es sólo capaz de 'referirse a' la memoria (de evocarla como tema, de procesarla como información), pero no de practicarla ni tampoco de expresar sus tormentos" (Residuos 30). Según Richard, en lugar de un posible desborde disruptivo de nombres, cuerpos, experiencias y memorias (Residuos 27), la paz democrática se "compra" en el Chile postdictatorial y neoliberal por medio de pactos y negociaciones, es decir, por medio de una diversidad regulada (Residuos 38 ).

En el trasfondo de los pactos negociados que recuerdan los tejemanejes de los grandes negocios y las coordinadas de otras transiciones políticas como la española, yace lo que Tomás Moulian llama la "negación casi atávica de lo 
que había sido la Unidad Popular", el rechazo concomitante "al "roto" y a sus ilusiones de poder [y] el repudio al comunismo y sus expectativas de un futuro sin clases" (25) ${ }^{2}$. Para Moulian, el "olvido y [la] desmovilización [se convirtieron] en las condiciones ideales de una transición paradigmática" (39), en la cual la "modernización política" estaba repleta de "resonancia[s] hobbesiana[s] de un orden impuesto por la amenaza del caos" (45). O de un orden impuesto por la amenaza del terror. Ahora bien, como ampliamente se demuestra en La batalla de Chile no es que la emoción esté necesariamente al servicio de una sociedad más política y económicamente justa o que necesariamente constituya uno de los pilares de una ética basada en la compasión o el "co-sentimiento" (el término es de Milan Kundera). Como bien se sabe, ciertas formas de la compasión resultan no solo compulsivas sino también cómplices de la normatividad sexual y del consumismo económico, entre otras cosas. Sea como fuere, lo que señala Moulian es cómo una emoción tan supuestamente primaria como el miedo puede implantarse, consciente e inconscientemente, para mantener en jaque a otras emociones y para controlar a gran parte de toda una sociedad. Sin duda es por "razones" similares que treinta y seis de los cuarenta colegios, escuelas y universidades a los que Guzmán se dirigió para proyectar La batalla de Chile veintitrés años después de su realización y grabar las reacciones del público rechazaron su petición. Como cuenta el mismo Guzmán, "me dijeron que los chicos se podían traumatizar, que el pasado había que olvidarlo" (citado en Ruffinelli 204) ${ }^{3}$.

La película en cuestión es la ya mencionada Chile, la memoria obstinada, que Jorge Ruffinelli ha caracterizado como "uno de los filmes más emocionales de Patricio Guzmán" (190-191). Las emociones captadas por la cámara y proyectadas en la pantalla surgen de dos fuentes: primero, la experiencia de unos estudiantes que ven por primera vez La batalla de Chile - un grupo de varones ya mayorcitos de la Universidad Católica, un grupo de colegialas de una preparatoria y un grupo de estudiantes mixtos de un instituto de teatro (Ruffinelli 204) - y, segundo, las reminiscencias de varios adultos que apoyaron y admiraron a Allende, entre

2 El pasaje más extenso reza así: "Fue una contrarrevolución, más precisamente una reacción contra un movimiento popular ascendente, un movimiento que a priori carecía de positividad pero que estaba preñado de negatividad. Por tanto, tenía que construir su identidad, la definición de sí en su propio desarrollo, en su despliegue, tuvo que superar la fase inicial en la cual su única marca y saber era la negación casi atávica de lo que había sido la Unidad Popular, no en-sí sino para sus enemigos. El contenido de la negación era el rechazo al 'roto' y a sus ilusiones de poder, el repudio al comunismo y sus expectativas de un futuro sin clases". (25).

3 "Guzmán pidió permiso en cuarenta colegios de Santiago. Cuatro contestaron afirmativamente" (Rufinelli 204). 
los cuales destacan su guardaespaldas; su viuda, Hortensia Bussi; Rodolfo Müller, padre de Jorge Müller Silva, el joven director de fotografía de La batalla de Chile que fue torturado en la infame Villa Grimaldi y luego "desaparecido"; y el anciano tío del propio Patricio Guzmán, Ignacio Valenzuela, quien ayudó a sacar la única copia de La batalla de Chile para Suecia y de ahí a Francia y a Cuba, donde se editó. Prohibida en Chile hasta 1996, La batalla de Chile, como de hecho todas las películas de Guzmán, ha tenido una visibilidad muy limitada en el país. Fue emitida, por fin, junto con Chile, la memoria obstinada, en 1999 y 2000 "por SKY, [una] compañía multinacional de televisión satelital, dentro del formato 'pago por visión', y desde entonces se hizo disponible sólo para aquellos hogares chilenos que podían costear una antena satelital" (Miller Klubock 279, traducción mía). En palabras de Thomas Miller Klubock, "[e]n la democracia neoliberal de Chile, la memoria y la historia ya no son objetos de censura por parte de la dictadura militar; hoy en día son mercancías que dependen de las vicisitudes del mercado y de las decisiones de las multinacionales" (279, traducción mía). Objetos de intercambio monetario, las películas también son objetos de estudio académico, incorporados, en ocasiones, en cursos de instrucción en universidades, colegios y escuelas, que también están cada vez más a la merced de las vicisitudes del mercado y las decisiones de las multinacionales.

Uno de los aspectos más llamativos de Chile, la memoria obstinada es lo que podría llamarse un mise en abîme pedagógica de la visión cinematográfica: la cámara de Guzmán va grabando las reacciones de los estudiantes chilenos mencionados arriba, muchos de los cuales habían nacido después del golpe o eran niños muy pequeños cuando ocurrió, mientras observan las imágenes de protestas populares, paros laborales y el bombardeo de La Moneda incluidas en La batalla de Chile. Pero la fuerza de esta película sobre el visionado de una película anterior va más allá de estos espectadores específicos, ubicados en lugares cercanos a los del golpe, aunque distantes en el tiempo, y asume una dinámica abierta e internacional. Al presentarla a un grupo de estudiantes de los Estados Unidos, en un seminario que impartí en Santiago de Chile hace dos años, veía a mis estudiantes mientras veían ellos a los estudiantes de Chile, la memoria obstinada que veían La batalla de Chile. Muchos de mis estudiantes lloraron, tocados tal vez por la fuerza contagiosa y catártica del llanto que vieron tanto en la pantalla como fuera de ella y por la representación y expresión de emociones en un espacio docente. Huelga decir que Guzmán, al igual que casi todos los directores, manipula el material que compone el documental que lleva su firma -el montaje casi nunca es del todo "inocente" - y que su deliberadamente pausado comentario en off "dirige" al público a oír, ver, pensar y sentir de ciertas formas 
más que de otras. Semejante manejo de las posibilidades expresivas del quehacer cinematográfico lleva al crítico Adrián Cangi a llamar a Guzmán un "fabulador" (158). Nostalgia de la luz se abre, después de todo, con un relato idealizado de un país "aislado del mundo [...] donde no pasaba nada" y donde los instrumentos del análisis científico - "el crujir del antiguo telescopio alemán" del planetario de Santiago - están acompañados visualmente por los enseres de un plácido interior doméstico y auditivamente por el susurro del viento y el canto de las aves. En Chile, la memoria obstinada, sin embargo, la cadencia engañosamente reconfortante de la voz del director se contrapone a la estridente sorna de los estudiantes de la Católica y a los llantos desconsolados de los estudiantes del instituto de teatro.

El recuerdo de la reacción emotiva e intelectual de "mis" estudiantes al ver estas dos películas me persigue e influencia mi propia visión de las películas de Guzmán, películas que lograron que varios de estos mismos estudiantes, cómodamente instalados en el privilegio, reconsiderasen algunas de sus afirmaciones anteriores acerca de las "virtudes" de Pinochet y de la "eficacia" económica del gobierno que lideró. Ninguno de nosotros era chileno. Todos éramos de otro país; mejor dicho, todos éramos de un país que había dejado unas huellas devastadoramente imperialistas en el país, Chile, en el que estábamos estudiando y que constituía el centro de nuestro trabajo intelectual. Pero he aquí cómo la mise en abîme pedagógica que Chile, la memoria obstinada escenifica se va ensanchando, poniendo en tela de juicio diferencias nacionales y distancias históricas y activando, de modo impredecible e irregular, el "co-sentimiento" que Kundera distingue de la compasión piadosa. Lejos de ser un mero efecto de tinta y papel o de sonidos e imágenes, el "co-sentimiento" pasa no solo por la descripción a veces testimonial de eventos traumáticos sino también por una maraña no "teorizable" de recuerdos tanto directos como indirectos, tanto personales como extrapersonales.

Marianne Hirsch, en una sutil lectura de fotografías familiares en las que la pérdida y la ausencia devienen imposiblemente presentes, acuñó el término "postmemoria" a fin de dar cuenta de aquellos recuerdos que no son los de un testigo ocular. En palabras de Hirsch:

La postmemoria se diferencia de la memoria por la distancia generacional y de la historia por la profunda conexión personal. La postmemoria es una forma poderosa y muy particular de memoria precisamente porque la relación con el objeto o la fuente [de la memoria] está mediada, no por el recuerdo individualizado sino por la participación y la creación imaginativas. [...] La postmemoria caracteriza la experiencia de todos aquellos que crecieron 
dominados por narrativas anteriores a su nacimiento, todos aquellos cuyas propias historias 'tardías' han sido vaciadas por las historias de la generación anterior, marcada por sucesos traumáticos que no se pueden entender ni recrear. He desarrollado [la] noción [de postmemoria] en relación con los sobrevivientes del Holocausto, pero creo que puede ser útil para describir otros recuerdos de segunda generación de eventos y experiencias cultural y colectivamente traumáticos. (22, traducción mía)

$\mathrm{Al}$ "desempacar" la memoria como función, práctica y experiencia de diferentes sujetos, Hirsch nos brinda una lectura de las capas subjetivas de la historia y de las tensiones y ataduras que la modulan. Desarrollada en relación con el Holocausto, la postmemoria está caracterizada por una apertura diaspórica. Pese a esa apertura diaspórica, la postmemoria, tal y como la formula Hirsch, se articula, sin embargo, en términos mayoritariamente generacionales y filiales.

De ahí que proponga suplementar la formulación de Hirsch con lo que podría llamarse, algo torpemente, la post-postmemoria, una memoria que se alimentaría de la "participación y creación imaginativas" señaladas por Hirsch y que reconoce que, en mayor o menor grado, todos los seres humanos "crece[mos] dominados por narrativas anteriores a [nuestro] nacimiento" (Hirsch 22, traducción mía). Con el término "post-postmemoria", quisiera señalar el complejo proceso en el cual los recuerdos, sentidos y sentimientos del pasado de un sujeto se entrelazan con los de otro, más allá de la unidad familiar que convencionalmente se asume como la base de la unidad nacional. Al proceder así, quisiera dinamizar algo internacional, en el sentido marxista, que habita lo global, en el sentido multinacional, al igual que algo a la vez universal, en el sentido de la mortal condición humana, y "poliversal", en el sentido de la diversidad y diferencia humanas. Tentativa, ecléctica y elíptica, la post-postmemoria invita a pensar, acaso a vivir, las grandes dicotomías de lo público y lo privado, lo colectivo y lo individual, lo foráneo y lo familiar como aspectos de un proceso dialéctico envolvente y no teológico en cual el ser se pliega sobre sí mismo y fuera de sí mismo, parcialmente alterado, desplazado y re-membrado.

Dicha re-membranza la anticipa Nelly Richard, quien, en un corto ensayo sobre Chile, la memoria obstinada, examina las tensiones diferenciales entre las fotografías documentales del bombardeo a La Moneda y el álbum de fotos de la boda de Juan Osses, uno de los pocos guardias de Allende que sobrevivió el golpe. De acuerdo con Richard, "se juega la tensión fotográfica entre la ritualidad privada del recuerdo sentimental y la monumentalidad pública de la cita histórica: doble trabajo de remembranza (remembrar: juntar miembros desperdigados) 
que busca exorcizar la pérdida con la reiteración de sucesivos mecanismos identificatorios" ("Con motivo" 58). La fotografía - literalmente, "la escritura de la luz" - desempeña un papel primordial en las películas más recientes de Guzmán pero también en prácticamente todas las asociaciones relacionadas con los desaparecidos, ese eufemismo, como lo llama el Equipo Argentino de Antropología Forense, con el que simultáneamente se evoca y acalla el secuestro, la detención, la tortura y el asesinato sistemáticos, actos de violencia casi siempre realizados - cabe recordarlo - en nombre de los "valores tradicionales de la familia" y de la nación. Para Hirsch:

[...] las fotografías en su perdurable conexión "umbilical" con la vida son precisamente el medio que conecta la remembranza, la memoria y la postmemoria de primera y segunda generación. Constituyen los restos, las fuentes fragmentarias y las piezas agujereadas del trabajo de la postmemoria. [Las fotografías] afirman la existencia del pasado y, con su plana bidimensionalidad, señalan su distancia irremediable. (23, traducción mía)

Una distancia irremediable, que también es una conexión umbilical perdurable, señala, desde luego, una contradicción que aumenta la fuerza dialéctica del acto supuestamente anodino de ver una fotografía.

Plana, bidimensional y siempre pretérita, la fotografía parecería ser el apoyo perfecto de la objetividad; después de todo, no es por nada que "objetivo" también significa "lente" . Y sin embargo, la fotografía también es el lugar de todo tipo de actividad memorable, una especie de escenario visual a través del cual el sujeto imaginativamente participa y crea, se recrea y re-memora a sí mismo, involucrándose en el acto de recordar. Recordar: Ernesto Malbrán, profesor, director y actor, nos recuerda en Chile, la memoria obstinada que "recordar" significa "volver a pasar por el corazón". La fotografía constituye, en definitiva, un rastro lumínico y material del pasado que puede dotarse de una gran fuerza cordial, un documento objetivo, pretérito y cerrado que puede abrirse, sin embargo, a toda suerte de emotividad subjetiva en el presente. Así descrita, la fotografía guarda más que una semejanza pasajera con el paisaje, no solo en su acepción más literal de contexto o base de la actividad humana sino también en su acepción más figurativa de sitio de inscripción. En una reciente entrevista, Guzmán reconoce el poder del paisaje, tanto el de la tierra como

4 Plana, bidimensional y siempre pretérita, la fotografía también guarda una relación estrecha con la muerte. Hirsch se nutre de La chambre claire de Roland Barthes, en la cual el crítico declara que "[a]vec la fotographie, nous entrons dans la Mort plate" (145, énfasis original). 
el del cielo, en relación con la capacidad fabuladora de la imagen visual: "el desierto," declara Guzmán, "es una máquina del tiempo llena de increíbles imágenes y muchas posibles películas" ("Ad Astra per Aspera" 23, traducción mía). Como el cineasta bien sabe, una fotografía y una película son también máquinas del tiempo llenas de imágenes increíbles y posibilidades infinitas. De hecho, todo el conjunto fracturado de la filmografía de Guzmán juega con las tensiones entre la inmovilidad y el movimiento que subyacen a las relaciones entre el cine, la fotografía y el paisaje y, en otro orden de significación, entre los vivos y los muertos.

En Chile, la memoria obstinada, la inmovilidad se presenta en la forma de varias fotografías, algunas de las cuales fueron fijadas como baldosas en el Muro de la Memoria en el Puente Bulnes de Santiago, lugar que sirvió de paredón de fusilamiento durante el golpe. Guzmán incluye imágenes del Muro de la Memoria en Nostalgia de la luz, justo después de entrevistar a Valentina, una joven astrónoma cuyos padres fueron detenidos y desaparecidos. Las imágenes de las baldosas fotográficas, a caballo entre la fotografía individualizada y el paisaje urbano masificado, revelan un estado de deterioro propio de su ubicación - y desubicación - en un espacio público. Aunque el estado de deterioro de las baldosas fotográficas ha incitado a algunos a pedir la restauración de un memorial que está siendo gradualmente erosionado por el sol, la lluvia y la contaminación, también sugiere una relación isomorfa con los restos del desierto de Atacama, lugar que Guzmán describe como "el gran libro del pasado donde se preservan dinosaurios, peces petrificados, esqueletos de exploradores europeos perdidos, contrabandistas, e incluso incas, puesto que el camino inca que comienza en Cuzco atravesaba el desierto" ("Ad Astra per Aspera" 21, traducción mía).

Las relaciones que Guzmán encuentra entre la fotografía, el cine y el paisaje recuerdan las que encuentra Raúl Zurita, controvertido poeta y artista visual chileno, entre la poesía y el paisaje. Para Zurita, las superficies de inscripción van desde el cielo azul de Nueva York (la efímera escritura en el cielo, en 1982, de 18 versos del poema titulado "La vida nueva") hasta el terreno rocoso del desierto de Atacama (la duradera escritura en la tierra, en 1993, del verso "ni pena ni miedo", que cierra un extenso libro de poesía también titulado La vida nueva). Como apunta Juan Soros, "ni pena ni miedo", verso excavado en la tierra, es apenas legible desde la tierra; su punto ideal de lectura es el cielo, desde el cual aparece casi como si estuviera impreso en ese gran libro del pasado que Guzmán identifica con el desierto de Atacama. Para Soros, el énfasis de este gran verso terrestre, que remite al land art o arte terrestre, recae no "en la ubicación de la 
obra, el site, sino en el punto de vista, en la mirada" $(136)^{5}$. El verso de Zurita evoca, inevitablemente, la pena y el miedo de la dictadura militar, su correlato más cercano en el tiempo, pero también evoca las antiguas líneas de Nazca en el Perú (125). El efecto es, por lo tanto, doble: por un lado, el verso constituye un guiño al reciente pasado nacional y por otro lado un guiño al lejano pasado prenacional, vaivén temporal que se agudiza todavía más en Nostalgia de la luz donde el tiempo reviste modalidades cósmicas.

En este documental todo se mezcla: el pasado con el presente, la tierra con el cielo y fragmentos de hueso con el polvo de las estrellas, ambos compuestos de sales de calcio al igual que el desierto. Además de ser el sitio de una importante instalación astronómica, el desierto de Atacama es también, como constata Guzmán:

[...] un sitio arqueológico absoluto y universal en el cual todo viene del pasado. La idea compartida de un pasado absoluto me resultó fundamental. Sin embargo [se me presentó un reto:] las diferentes historias de arqueólogos, geólogos, mujeres y astrónomos se erigían como pilares separados y fue necesario conectarlas de alguna manera. (“Ad Astra per Aspera" 21, traducción mía)

Guzmán, quien ha pasado la mayor parte de su vida en el exilio, no pone límites nacionales o familiares a la "idea compartida" del pasado, aunque sus obras están profundamente marcadas tanto por lo nacional como por lo familiar. Aun así - o tal vez por esto mismo - mientras señala la universalidad material de planetas, estrellas y demás "cuerpos celestes", también reconoce la fragilidad de estos y otros "cuerpos" y, cómo no, de sus historias y discursos. La importancia que Guzmán concede a las narraciones de las mujeres que escarban el desierto y tamizan la arena en busca de los huesos de sus seres queridos las pone en una relación de tensa y frágil igualdad con los astrónomos y los geólogos que estudian las rocas y las estrellas. La relación es tensa y frágil porque, como declara una de las mujeres, Violeta Berríos, de 70 años, ellas, con su innegable subjetividad personal, y no los científicos, con su pretendida objetividad profesional, son "la lepra de Chile". Al reconocer la autoridad narrativa de estas mujeres, Guzmán también las reconoce como sujetos del saber. Se trata, claro está, de un saber que los poderes existentes han tendido a descartar e incluso a menospreciar, como si

5 Para más información sobre la poesía de Zurita y/o el land art o arte terrestre, véanse los artículos de Jens Andermann, Macarena Ortúzar y Benoît Santini. La escritura celeste, fotografiada, forma parte del poemario Anteparaíso de Zurita. De Zurita, véanse también Purgatorio y La vida nueva. 
estas buscadoras no tuvieran nada que contar, como si no contaran nada. Cabe mencionar que el proyecto de la película fue rechazado tanto por FONDART como por CORFo (la Corporación de Fomento de la Producción de Chile), las dos principales fuentes de financiación del gobierno chileno (Guzmán, "La odisea financiera" 27). Afortunadamente, como precisa Guzmán, algunos de los científicos que entrevistó sí "conectaron" con las mujeres y supieron apreciar sus historias, sus actos y sus saberes, superando por lo tanto, aunque solo fuera por un momento, la separación entre unos y otras que tanto había temido el cineasta ${ }^{6}$.

Las relaciones entre seres humanos se complementan y complican, como ya se ha venido insinuando, con las relaciones entre medios y materiales. Si en Chile, la memoria obstinada Guzmán "recicla" fragmentos de La batalla de Chile, en $\mathcal{N o s}$ talgia de la luz, "recicla" - en el mejor sentido ecologista del término- fotografías del Muro de la Memoria, de la investigación astronómica y del foto-ensayo Flores en el desierto de la documentalista norteamericana Paula Allen, que presenta a las mujeres de Camala, en la región de Atacama, mostrando otras fotografías, anteriores al golpe, de sus esposos, padres, hermanos, niños, amantes y compañeros perdidos. También las presenta sentadas en sus casas; recorriendo el desierto y conmemorando a los desaparecidos y muertos. Allen dice que se enteró por primera vez de los desaparecidos del desierto de Atacama, y de Chile en general, por medio de la película Dance of Hope o Baile de la esperanza, dirigida en 1989 por Deborah Shaffer con la participación de los músicos Sting y Peter Gabriel. Las fotografías y las películas, al igual que las historias y los testimonios, se van sobreponiendo, pues, como si fueran capas geológicas o planos astrales.

Sin lazos familiares, nacionales o lingüísticos, Allen llega a Chile y produce un trabajo de la post-postmemoria, visitando Calama y entrevistando a las mujeres que allí residen. Como "participante observadora", Allen recalca no su distancia crítica u objetividad profesional sino su "compromiso" con las mujeres de Calama. Al menos dos de las mujeres, Violeta Berríos Águila y Victoria (Vicky) Saavedra, aparecen también en Nostalgia de la luz, sus figuras antaño inmóviles en blanco y negro ahora "animadas" en tecnicolor. Aunque Allen, a diferencia de Guzmán, no puede echar mano de una versión idealizada de su pasado infantil (aspecto fundamental de la nostalgia del título de la película), intenta

6 No es, en otras palabras, que el análisis científico y la subjetividad siempre estén en desacuerdo (de hecho, por lo menos uno de los astrónomos que Guzmán entrevista hace comentarios emocionalmente cargados y ricamente poéticos), sino que muchos de los que tienen posiciones de poder económico y político, que no son investigadores de las estrellas ni de los huesos, pueden asestar una desconexión en contraste con las conexiones que Guzmán, a través de sus espectadores, encuentra. 
demostrar en cambio su compromiso ético y político, intelectual y emocional con las buscadoras del desierto. Afirma que "lloró con ellas cuando no pudieron recuperar los cuerpos de los hombres que amaban y [cuando] salieron de nuevo al día siguiente con linternas y palas siguiendo los rumores y la intuición" (18). La referencia a las lágrimas en medio de tanta sequedad se entrecruza con la historia que narra Leonilda Rivas sobre el abuso que sufrió a manos de los soldados: "Yo estaba en Antofagasta cuando se llevaron a mi hijo Manuel a la prisión. Viajé de vuelta a Calama con tortillas para dárselas. Cuando llegué a la prisión, algunos soldados comenzaron a pegarme. Yo comencé a llorar. Un teniente vino y me dijo, "Váyase de aquí señora, nadie viene aquí a llorar"' (22). La referencia al llanto y a su prohibición autoritaria confiere un peso personal a las teorizaciones más bien abstractas de Richard y Moulian con las que abrí este artículo.

Ancladas en un saber narrativo, las fotografías adquieren una densidad emocional que coincide con el relato que cuenta Allen acerca de su relación con las mujeres fotografiadas: "[i]nspirada por [aquellas mujeres] que [...] se negaban a ser silenciadas, he aprendido que es posible invocar la dignidad propia en contra de la injusticia, conservando así el espíritu del amor debajo del peso de un enorme sufrimiento" (19). El tenor humanista de las palabras de Allen corre el riesgo, sin embargo, de caer en una trivialidad de índole verbal, no visual, lo cual incita a Tierney-Tello a comentar, en un gesto a estas alturas casi inevitable en la crítica cultural, que dicha autoevaluación, aunque se alimente de empatía e compasión, puede resultar dudosa cuando conlleva la aparentemente fácil apropiación del sufrimiento de los demás (88). A continuación cita a Hirsch, quien advierte que "'el reto para el artista post-memorial [o tal vez, más precisamente, el artista post-post-memorial], es encontrar el punto de equilibrio que permita al espectador entrar en la imagen y así 'visualizar' el desastre, pero que a la vez desautorice una identificación excesiva que hace desaparecer toda distancia, creando un acceso demasiado accesible, demasiado fácil"' (citado por Tierney-Tello 88, traducción mía). Resta por ver, sin embargo, qué hace que la identificación (o la des-identificación) resulte excesiva y cuál es el punto de equilibrio correcto. Con profundo respeto, yo diría que dichos actos de equilibrio, dichos malabarismos, por importantes que sean, están destinados al fracaso, al menos si se supone una regla general válida para todos.

En Nostalgia de la luz el fracaso asoma por doquier: en el proyecto de justicia económica y social violentado por los poderes fácticos del orden establecido; en la ilusión sombría de encontrar los restos de unos seres queridos destrozados por el régimen militar; en el intento de captar el pasado y de mitigar su dolor; en la esperanza de superar la pena y el miedo y de comenzar una vida nueva; en la 
creación de obras de arte en las que el compromiso y la denuncia se compaginan, tensamente, con la belleza y la emotividad; en la valoración de saberes e historias que no se limitan a las esferas consagradas de las ciencias y las humanidades en una época dominada por el neoliberalismo globalizado. Es el fracaso de la memoria, pero también del olvido. Como dice Guzmán al final de Nostalgia de la luz, años después de La batalla de Chile y de Chile, la memoria obstinada: "los que tienen memoria son capaces de vivir en el frágil tiempo presente; los que no la tienen no viven en ninguna parte. Cada noche lentamente, impasible, el centro de la galaxia pasa por encima de Santiago"7. Y cada día, lentamente, impasible, el centro de la galaxia lo deja atrás.

\section{Obras citadas}

Allen, Paula. Flores en el desierto/Flowers in the Desert. Prólogo de Isabel Allende.

Presentación de Patricia Verdugo. Santiago: Editorial Cuarto Propio, 1999. Impreso.

Andermann, Jens. "Expanded Fields: Postdictatorship and the Landscape". Fournal of Latin American Studies: Travesía 21.2 (2012): 165-187. Impreso.

Barthes, Roland. La chambre claire: note sure la photographie. París: Éditions de l'Étoile/Gallimard/Le Seuil, 1980. Impreso.

Blaine, Patrick. "Representing Absences in the Postdictatorial Documentary Cinema of Patricio Guzmán". Latin American Perspectives 40 (2013): 114-130. Impreso.

Cangi, Adrián. "Poética de la luz, política del gesto." Revista Nomadías 14 (2011): 157-169. Impreso.

"Crisis". Online Etymology Dictionary. Web. 18 abril de 2015.

"Disaster". Online Etymology Dictionary. Web. 18 abril de 2015.

Guzmán, Patricio. "À propos de son film Nostalgie de la lumière". Essaim 26 (2011): 115135. Impreso.

"Ad Astra per Aspera: An Interview with Patricio Guzmán". Por Haden Guest y Eduardo Ledesma. Gineaste (2011): 20-25. Impreso.

Chile, la memoria obstinada. La Sept-Arte, Les Films d'Ici, National Film Board of Canada, 1997. Impreso.

Nostalgia de la luz. Atacama Productions, Blinker Filmproduktion, Westdeutscher Rundfunk, Cronomedia, 2010. Impreso.

7 Después del gesto "trascendental" de Nostalgia de la luz, en la que la tierra se relaciona con el cielo, no es de sorprender que Guzmán se haya fijado en las profundidades del océano y en las relaciones entre la tierra y el agua en su nuevo documental, El botón de nácar (2015), estrenado después de redactado el presente ensayo. 
"La odisea financiera de Nostalgia de la luz". Academia: Revista de Cine Español (2011): 26-27. Impreso.

Hirsch, Marianne. Family Frames: Photography, Narrative and Postmemory.

Cambridge: Harvard University Press, 1997. Impreso.

Miller Klubock, Thomas. "History and Memory in Neoliberal Chile: Patricio Guzmán's Obstinate Memory and The Battle of Chile". Radical History Review 85 (2003): 272281. Impreso.

Moulian, Tomás. Chile actual: anatomía de un mito. Santiago: LOM/ARCIS, 1997. Impreso.

Ortega Breña, Mariana, y Walescka Pino-Ojeda. "Latent Image: Chilean Cinema and the Abject." Latin American Perspectives 36.5 (2009): 133-146. Impreso.

Ortúzar, Macarena. "Anteparaíso de Raúl Zurita: Una copia feliz del Edén”. Hispamérica 33.98 (2004): 107-113. Impreso.

Richard, Nelly. "Con motivo del 11 de septiembre: notas sobre La memoria obstinada (1996) de Patricio Guzmán". Revista de Crítica Cultural 15 (1997): 54-61. Impreso. Residuos y metáforas (ensayos de crítica cultural sobre el Chile de la Transición). Santiago: Editorial Cuarto Propio, 1998. Impreso.

Ruffinelli, Jorge. El cine de Patricio Guzmán: en busca de las imágenes verdaderas. Santiago: Uqbar Editores, 2008. Impreso.

Santini, Benoît. "El paisaje, instrumento de denuncia en la obra de Raúl Zurita". Zurita $x$ 60. Eds. Chiara Bolognese et al. Santiago: Editorial MAGO, 2011. 77-118. Impreso.

__ "Entrevista al poeta chileno Raúl Zurita". Caravelle 91 (2008): 203-222. Impreso.

Soros, Juan. "Del Land Art al campo iconotextual en la obra poética de Raúl Zurita." Zurita x 60. Eds. Chiara Bolognese et al. Santiago: Editorial MAGO, 2011. 121-138. Impreso.

Tierney-Tello, Mary Beth. "On Making Images Speak: Writing and Photography in Three Texts from Chile". Photography and Writing in Latin America: Double Exposures. Eds. Marcy E. Schwartz y Mary Beth Tierney-Tello. Albuquerque: University of New Mexico Press, 2006. 87-113. Impreso.

Valenzuela, Alejandro. "Patricio Guzmán: Nostalgia de la luz. Chile, Alemania, Francia 2010. 90 minutos". Cátedra de Artes 9 (2011): 118-122. Impreso.

Zurita, Raúl. Anteparaíso. Santiago: Editores Asociados, 1982. Impreso. Purgatorio. Santiago: Editorial Universitaria, 1979. Impreso. La vida nueva. Santiago: Editorial Universitaria, 1994. Impreso. 